\title{
Stroop-Like Interference in the Fruit Stroop Test in Typical Development
}

\author{
Hideyuki Okuzumi1, Yoshifumi Ikeda², Nao Otsuka1, Ryotaro Saito1, Yuhei Oi'1, \\ Shogo Hirata ${ }^{3}$, Koichi Haishi' ${ }^{4}$, Mitsuru Kokubun' ${ }^{1}$ \\ ${ }^{1}$ Tokyo Gakugei University, Tokyo, Japan \\ ${ }^{2}$ Joetsu University of Education, Niigata, Japan \\ ${ }^{3}$ Chiba University, Chiba, Japan \\ ${ }^{4}$ Saitama University, Saitama, Japan \\ Email: yosifumi@juen.ac.jp
}

Received 21 March 2015; accepted 17 April 2015; published 23 April 2015

Copyright (C) 2015 by authors and Scientific Research Publishing Inc.

This work is licensed under the Creative Commons Attribution International License (CC BY).

http://creativecommons.org/licenses/by/4.0/

c) (7) Open Access

\section{Abstract}

This study examined Stroop-like interference in the fruit Stroop test among 2715 - 12-year-old children and young adults divided into five age groups: 645 - 6-year-olds, 657 - 8-year-olds, 609 10-year-olds, 4611 - 12-year-olds, and 36 young adults (18 - 23-year-olds). Participants were administered a paper-and-pencil version of the fruit Stroop test, which includes the canonical color task, the superficial color task, and the fruit name task. In these tasks, participants were presented with line-drawings of fruits having strongly associated colors (e.g., yellow banana) and were asked to name the ink colors of the fruits, name the colors the fruit "should be", or read the fruit name. The results indicated robust interference in the canonical color task of the fruit Stroop test, suggesting that this task is useful to assess individual differences of inhibitory control in typical development.

\section{Keywords}

Inhibitory Control, Executive Function, Children

\section{Introduction}

Inhibitory control is the ability to suppress competing, dominant, automatic or prepotent cognitive processing at perceptual, intermediate, and output stages (Friedman \& Miyake, 2004; Nigg, 2000). That ability is used when the cognitive processing must be suppressed merely because it is inappropriate and when the cognitive processing must be suppressed in favor of a subdominant but appropriate one. Inhibitory control putatively plays a cru- 
cially important role in maintaining concentration and performing goal-directed behaviors (Anderson, 2002; Diamond, 2013; Miyake \& Friedman, 2012). Deficits in inhibitory control have also been implicated in behavioral problems associated with developmental disorders such as attention deficit hyperactivity disorder (ADHD) (Barkley, 1997; Ozonoff \& Jensen, 1999; Song \& Hakoda, 2011; Yasumura et al., 2014). Inhibitory control is a key cognitive function of typical and atypical child development.

Many efforts have been undertaken to investigate the typical development of inhibitory control. Among various measures, the most classic is the Stroop color-word test. In this test, individuals are presented with incongruent color word stimuli, for instance the word red printed in blue ink. They are then requested to name the ink color while inhibiting the prepotent tendency of word-reading. The response time cost in color-naming of the incongruent stimuli versus neutral stimuli, such as a blue rectangle, indicates the Stroop interference, also known as the Stroop effect. However, because the Stroop color-word test requires well-developed reading skill, its effectiveness is limited when used with children younger than around 7 years, who have little or no reading ability (Brocki \& Bohlin, 2004; Wright, Waterman, Prescott, \& Murdoch-Eaton, 2003).

Addressing that important limitation of the classic Stroop color-word test, attempts have been undertaken to develop new measures based in principle on Stroop interference, i.e., two-dimensional stimuli associated with two different and competing responses, but which require no reading skill. Such methods are the color-object Stroop task (Prevor \& Diamond, 2005), the animal Stroop task (Nichelli, Scala, Vago, Riva, \& Bulgheroni, 2005; Wright et al., 2003), the Real Animal Size Test (Catale \& Meulemans, 2009; Ikeda, Okuzumi, \& Kokubun, 2013a), and the Pictorial Animal Size Test (Ikeda et al., 2013a), and the fruit Stroop task (Archibald \& Kerns, 1999). Among them, the fruit Stroop task has been used frequently in recent developmental studies (Loher \& Roebers, 2013; Macdonald, Beauchamp, Crigan, \& Anderson, 2014; Michel \& Roebers, 2008; Neuenschwander, Cimeli, Röthlisberger, \& Roebers, 2013; Roebers, Röthlisberger, Neuenschwander, Cimeli, Michel, \& Jäger, 2014; Röthlisberger, Neuenschwander, Cimeli, \& Roebers, 2013).

Here, it is noteworthy that in the Stroop paradigm, where two-dimensional stimulus associated with two different and competing responses is presented, interference can occur in two "directions" as one from Dimension A on Dimension B and vice versa. For instance, in the Stroop Color-Word test, although Stroop interference is a phenomenon observed when word reading interferes with color naming, interference of color naming with word reading is also observable when reading the color word in an incongruent color, i.e., the reverse-Stroop interference, although it is less than the Stroop interference when one must make an oral response (Ikeda, Hirata, Okuzumi, \& Kokubun, 2010; MacLeod, 1991; Pritchatt, 1968). Consequently, it is necessary to investigate interference in both directions when one infers how processing of one dimension interferes with that of the other dimension. However, most studies that have been undertaken to develop Stroop-like tasks have examined interference in only one direction.

This study was conducted to investigate mechanisms of interference in the fruit Stroop task. With this aim, this study investigated performances on the blocked paper-and-pencil version of the fruit Stroop test in typically developing children and young adults. In this test, individuals were presented with line drawings of fruits which have a strongly associated color (canonical color; e.g., red for strawberry) and were asked to name their canonical colors. Presumably, naming canonical colors interferes with naming superficial ink colors of the fruits presented when they are colored inappropriately (e.g., strawberry in yellow). This study examined differences between interference from superficial color to canonical color and interference from canonical color to superficial color as well as interference from superficial color to word reading.

\section{Method}

Participants. Participants were 271 children and adults of five age groups: 1) 5 - 6 yr, 64 children (28 boys, 36 girls; $M$ age $=70.6$ mo, age range $=60-83 \mathrm{mo}$ ); 2$) 7-8$ yr, 65 children $(32$ boys, 33 girls; $M$ age $=94.9$ mo, age range = $84-107 \mathrm{mo}$ ); 3) $9-10 \mathrm{yr}, 60$ children (29 boys, 31 girls; $M$ age = 119.1 mo, age range = $108-130$ mo); 4) $11-12$ yr, 46 children (22 boys, 24 girls; $M$ age = 141.9 mo, age range = $132-151$ mo); and 5) 36 young adults ( 19 men, 17 women; $M$ age $=21.3$ yo, age range $=18-23$ yo). The divisions between the age groups were determined based on chronological age. Across age groups, almost all participants were middle-class and Asian. Children were recruited through local mainstream preschool and elementary school programs. Adults were recruited from a university.

This study included only participants with reading ability. Some preschool children were excluded from this 
study because of their lack of reading ability. An additional 29 participants were tested but were unable to provide data for analyses because they seemed not to understand the rules properly. Moreover, an additional 54 participants were tested but their data were excluded from analyses because they were identified as outlier cases. Details are described in the Results section.

Measures. All participants were administered a paper-and-pencil version of the fruit Stroop test. This test comprised three tasks with two conditions respectively, i.e., six conditions in total, in which pictures of fruits or geometric figures were depicted on six separate sheets of paper (see Figure 1).

Canonical color task. In this task, participants were presented with line-drawings of fruits along with canonical colors (strawberry associated with red, banana associated with yellow, and melon associated with green). In the control condition (Test 1), three colorless line drawings of fruits (strawberry, banana, and melon) were presented one by one, requiring participants to choose from the three colored rectangles (red, yellow, green) printed on the right side of the test sheet corresponding to the canonical color the stimulus represented. In the interference condition (Test 2), the three line drawings of fruits printed in a noncanonical color of the same three colors (e.g., green strawberry, red banana, yellow melon) were presented one by one, requiring participants to make a choice from the three colored rectangles (red, yellow, green) printed on the right side of the test sheet corresponding to the canonical color the stimulus represented. Therefore, participants were compelled to inhibit a response to the superficial color and to give a response related to the fruit's canonical color in the interference condition.

Superficial color task. In the control condition (Test 3), three geometric figures (a triangle, a square, and a circle) colored in red, yellow, or green were presented one by one, requiring participants to choose from the three colored rectangles (red, yellow, green) printed on the right side of the test sheet corresponding to the superficial ink color the stimulus represented. In the interference condition (Test 4), the three line drawings of

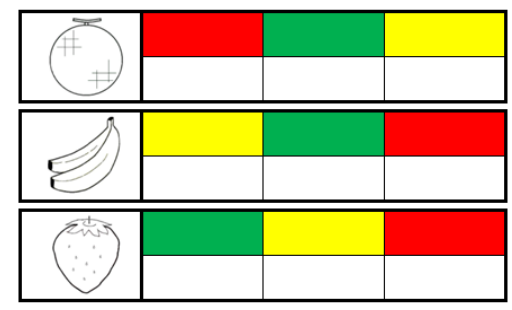

Test 1 Canonical color task (control)

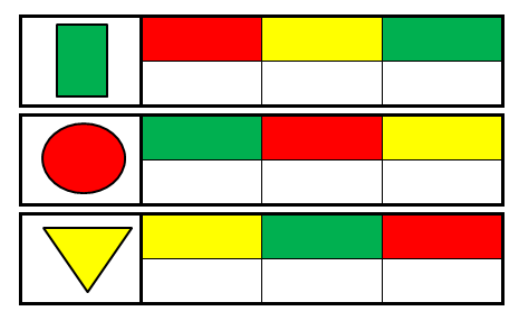

Test 3 Superficial color task (control)

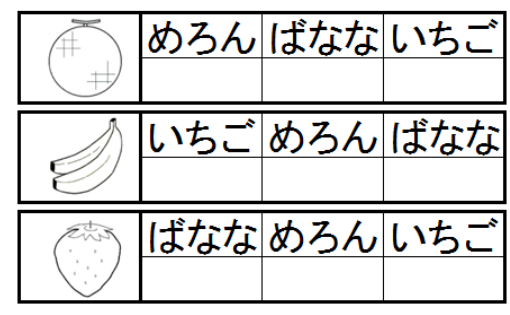

Test 5 Fruit name task (control)

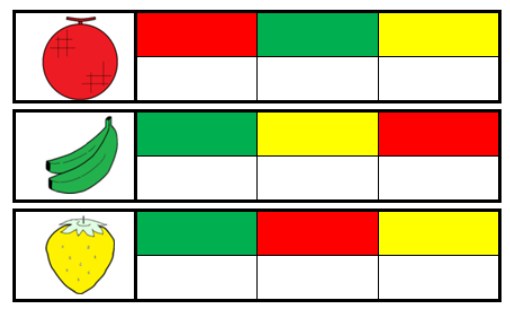

Test 2 Canonical color task (interference)

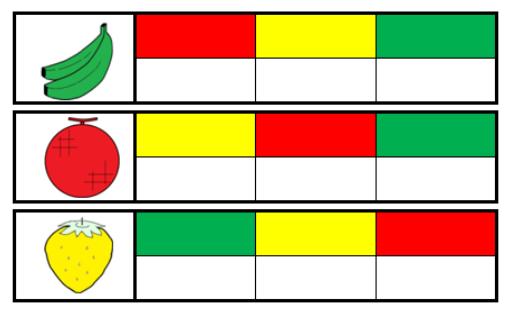

Test 4 Superficial color task (interference)

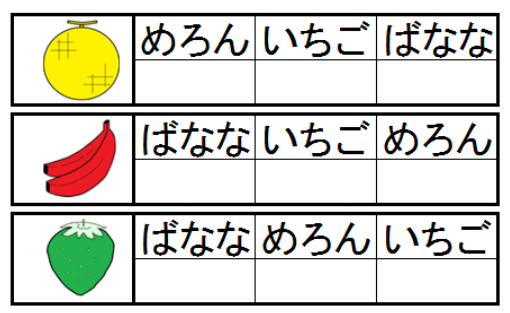

Test 6 Fruit name task (interference)

Figure 1. Examples of the six conditions in the fruit Stroop test. For Test 5 and Test 6, three words were used: “ばなな” refers to “banana”; “いちご” “strawberry”; and “めろん” "melon". 
fruits printed in a noncanonical color of the same three colors (e.g., green strawberry, red banana, yellow melon) were presented one by one, requiring participants to make a choice from the three colored rectangles (red, yellow, green) printed on the right side of the test sheet corresponding to the superficial ink color the stimulus represented. Therefore, participants were compelled to inhibit a response to the superficial color and give a response related to the fruit's superficial color in the interference condition.

Fruit name task. In this task, participants were presented with line-drawings of fruits that have strongly associated colors (strawberry, banana, and melon). In the control condition (Test 5), three colorless line drawings of fruits (strawberry, banana, and melon) were presented one by one, requiring participants to choose from the three words ("strawberry", "banana”, "melon” in Japanese) printed on the right side of the test sheet corresponding to the meaning the stimulus represented. In the interference condition (Test 6), the three line drawings of fruits printed in a noncanonical color of the same three colors (e.g., green strawberry, red banana, yellow melon) were presented one by one, requiring participants to make a choice from the three words ("strawberry", "banana”, "melon” in Japanese) printed on the right side of the test sheet corresponding to the meaning the stimulus represented. Therefore, participants were compelled to inhibit a response to the superficial color and give a response related to the fruit's name in the interference condition.

Procedures. Participants were tested in groups in quiet and illuminated rooms at a kindergarten, a school, or a university. At arrival, a participant was asked to be seated in front of the task papers placed on a desk. Then each participant was administered four preliminary tests. Each was confirmed to be able to recognize colors, the fruits' canonical colors, names of the fruits in written Japanese, and names of colors in written Japanese (otherwise a participant was not administered the tasks further and was excluded from participants in this study; five 5-year-olds and three 6-year-olds were unable to recognize names of the fruits and/or names of colors in written Japanese).

Subsequently, each was presented with a sheet of paper (A3) for each condition. Each sheet of paper consisted of 6 practice trials and 60 test trials. The participants were asked, respectively, to perform the practice and test trials as quickly and as accurately as possible for $10 \mathrm{~s}$ and $30 \mathrm{~s}$. Each used a pen to make a choice from the three columns on the right side of the test sheet, thereby allowing group administration of the tests. In addition, a participant was asked to correct errors when detecting errors by drawing double lines on them and making the response that should have been made. The order of the three tasks was counterbalanced among the participants. For each task, the order of the two conditions was randomized among the participants.

Analysis. For each test, quantities of correct responses out of 60 test trials were recorded. As indices of inhibitory control, the interference scores were calculated using the formula shown below:

Interference score $=100 \times$ (correct responses in the control condition - correct responses in the interference condition)/correct responses in the control condition.

For statistical analyses, software (SPSS 19.0 for Windows) was used.

Ethical approval. Our experimental protocol was administered in accordance with the guidelines of the Declaration of Helsinki and was approved by the institutional review board. Informed consent was obtained from all adult participants and from a parent of each child participant before the assessment session.

\section{Results}

Treatment of the data. Children who seemed not to understand the rules properly were excluded from this study. Because some could not be administered all three tasks, 85 - 6-year-olds, 107 - 8-year-olds, 49 10-year-olds, and 1011 - 12-year-olds were excluded. Moreover, two 8-year-olds were excluded because they were unable to follow the rules. One 5-year-old hesitated to continue the test during the session. Data of an additional 54 participants were excluded from analyses because they were identified as outlier cases (defined as “atypical values” by the SPSS 19 Explore command) for each set of dependent variables (quantities of correct responses and interference scores).

Quantities of correct responses. Items were counted as correct responses when a participant checked correctly as well as when a participant checked appropriately after error correction. Table 1 shows means and standard deviations for the quantities of correct responses in the control and interference conditions for each task of the fruit Stroop test. A 3 (task) $\times 2$ (condition) $\times 5$ (age group) mixed analysis of variance was conducted for the quantities of correct responses. Significance was found for the three main effects (age group: $F_{4,266}=530.81$, $p<.001$, partial $\eta^{2}=.89$; task: $F_{2,532}=972.56, p<.001$, partial $\eta^{2}=.79$; and condition: $F_{1,266}=608.61, p$ 
Table 1. Quantities of correct responses in each task of the fruit Stroop test.

\begin{tabular}{ccccccccccc}
\hline & 5 - 6 years old & \multicolumn{2}{c}{7 - 8 years old } & \multicolumn{2}{c}{9 - 10 years old } & 11 - 12 years old & \multicolumn{2}{c}{ Young adults } \\
\hline & $M$ & $S D$ & $M$ & $S D$ & $M$ & $S D$ & $M$ & $S D$ & $M$ & $S D$ \\
\hline Test 1 (canonical color control) & 13.4 & 3.7 & 23.7 & 4.4 & 28.6 & 3.1 & 34.6 & 3.4 & 42.6 & 4.3 \\
Test 2 (canonical color interference) & 10.9 & 3.2 & 19.2 & 4.2 & 23.1 & 3.5 & 28.1 & 3.1 & 35.0 & 4.1 \\
Test 3 (superficial color control) & 14.2 & 4.5 & 27.2 & 4.7 & 31.3 & 3.9 & 39.1 & 3.7 & 47.1 & 4.4 \\
Test 4 (superficial color interference) & 14.6 & 4.3 & 26.4 & 4.7 & 30.1 & 3.8 & 37.4 & 3.0 & 44.5 & 4.2 \\
Test 5 (fruit name control) & 11.6 & 3.2 & 21.4 & 3.6 & 24.8 & 3.6 & 30.0 & 2.9 & 35.6 & 3.1 \\
Test 6 (fruit name interference) & 11.0 & 3.2 & 20.1 & 3.6 & 24.0 & 3.2 & 28.5 & 3.4 & 33.7 & 3.7 \\
\hline
\end{tabular}

$<.001$, partial $\eta^{2}=.70$ ), the three two-way interactions (interaction between the task and age group: $F_{8,532}=$ 245.47, $p<.001$, partial $\eta^{2}=.34$; interaction between the condition and age group: $F_{4,266}=103.27, p<.001$, partial $\eta^{2}=.27$; and interaction between the task and condition: $F_{2,532}=727.56, p<.001$, partial $\left.\eta^{2}=.44\right)$, and the three-way interaction between age group, task, and condition $\left(F_{8,532}=15.36, p<.001\right.$, partial $\left.\eta^{2}=.62\right)$.

Interference score. Table 2 presents means and standard deviations for the interference scores in each task of the fruit Stroop test. A 3 (task) $\times 5$ (age group) mixed analysis of variance was conducted for the interference scores. The analysis revealed a significant effect for task $\left(F_{2,532}=155.99, p<.001\right.$, partial $\left.\eta^{2}=.37\right)$, for age group $\left(F_{4,266}=381.26, p<.05\right.$, partial $\left.\eta^{2}=.37\right)$, and for interaction between task and age group $\left(F_{8,532}=271.90\right.$, $p<.05$, partial $\eta^{2}=.32$ ). Post hoc Bonferroni tests yielded significant differences between the canonical color task and the superficial color task and between the canonical color task and the fruit name task for all age groups $(p<.001)$, and significant difference between the superficial color task and the fruit name task for the 5 - 6-yearolds $(p<.001)$. The analysis also revealed significant differences between 5 - 6-year-olds and the other age groups in the Superficial color task $(p<.01)$. The other comparisons showed no significant differences.

\section{Discussion}

In this study, data were analyzed for quantity of correct responses and the interference score. Although error rates are interpreted as an index of inhibitory control, those less able to suppress distracting information are more prone to errors (e.g., McDowd, Oseas-Kreger, \& Filion, 1995), error rates were not analyzed because the participants showed very accurate performances. Errors were few and not normally distributed. However, the numbers of errors were considered for quantity of correct response, and therefore the interference score. The difference between the interference condition and the control condition is of particular interest because a measure of interference occurred, i.e., inhibitory control. To investigate the interference more precisely at the level of the individual, the interference score was analyzed. Although the difference score has been used in many studies conducted to date, recent studies have used the interference score as calculated in this study, which excludes any influence of an individual's performance level (Ikeda, Hirata, Maeda, Okuzumi, Kokubun, Ambe et al., 2013; Ikeda, Hirata, Okuzumi, \& Kokubun, 2010; Ikeda, Okuzumi, Kokubun, \& Haishi, 2011; Ikeda, Okuzumi, \& Kokubun, 2013a, 2013b; Ludwig, Borella, Tettamanti, \& de Ribaupierre, 2010; Song \& Hakoda, 2011). Therefore, this study does not assess the results of the quantity of correct responses further.

Differences in interference scores were observed among the tasks. Interference was greatest in the canonical color task: greater than in the superficial color task or the fruit name task, among the latter of which no further difference was observed except in the youngest age group. According to the Parallel Distributed Processing (PDP) model (Cohen, Dunbar, \& McClelland, 1990), the difference in strength of processing between two dimensions of stimulus causes asymmetric interference. Stronger processing interferes with weaker processing, but not vice versa. Comparison between the canonical color task and the superficial color task indicates that processing the superficial color interfered with processing the canonical color, suggesting that processing the superficial color is stronger. In addition, comparison between the canonical color task and the fruit name task indicates that processing the superficial color did interfere with processing of the canonical color but not with processing fruit's words, suggesting that interference occurs when representations of colors compete for particular resources of processing and that naming fruit words does not induce processing of the colors. 
Table 2. Interference scores in the fruit Stroop test.

\begin{tabular}{ccccccccccc}
\hline & $5-6$ years old & \multicolumn{2}{c}{7 - 8 years old } & \multicolumn{2}{c}{$9-10$ years old } & \multicolumn{2}{c}{11 - 12 years old } & \multicolumn{2}{c}{ Young adults } \\
& $M$ & $S D$ & $M$ & $S D$ & $M$ & $S D$ & $M$ & $S D$ & $M$ & $S D$ \\
\hline Canonical color task & 17.9 & 14.9 & 18.5 & 12.4 & 18.9 & 10.3 & 18.5 & 8.5 & 17.6 & 8.7 \\
Superficial color task & -4.3 & 17.4 & 2.6 & 9.7 & 3.2 & 9.2 & 4.1 & 7.6 & 5.4 & 5.7 \\
Fruit name task & 3.6 & 16.9 & 5.7 & 9.7 & 2.5 & 11.6 & 4.7 & 8.1 & 5.2 & 8.0 \\
\hline
\end{tabular}

Considering age-related trends specifically, development of inhibitory control was not found for the interference score. This is not consistent with the results obtained by Archibald and Kerns (1999), but it is consistent with the results obtained by an earlier study using the fruit Stroop test (defined here as the canonical color task), which showed only a trend toward reduced interference with age (MacDonald et al., 2014). This discrepancy might derive from the difference in procedures such as response mode (oral vs. manual), the stimuli used, and the participant's age. However, the results of this study indicated high variability of interference, thereby suggesting that the fruit Stroop test is a useful test to assess individual differences of inhibitory control.

\section{Conclusion}

Results of this study demonstrated robust interference in the canonical color task of the fruit Stroop test. Although reduced interference with age was not observed in the canonical color task, this task might be a useful tool to assess individual differences of inhibitory control given the high variation of the interference scores.

\section{Acknowledgements}

The authors thank all children and teachers who participated in the study as well as the kindergarten and school administrators who supported data collection.

\section{References}

Anderson, P. (2002). Assessment and Development of Executive Function (EF) during Childhood. Child Neuropsychology, 8, 71-82. http://dx.doi.org/10.1076/chin.8.2.71.8724

Archibald, S. J., \& Kerns, K. A. (1999). Identification and Description of New Tests of Executive Functioning in Children. Child Neuropsychology, 5, 115-129. http://dx.doi.org/10.1076/chin.5.2.115.3167

Barkley, R. A. (1997). Behavioral Inhibition, Sustained Attention, and Executive Functions: Constructing a Unifying Theory of ADHD. Psychological Bulletin, 121, 65-94. http://dx.doi.org/10.1037/0033-2909.121.1.65

Brocki, K. C., \& Bohlin, G. (2004). Executive Functions in Children Aged 6 to 13: A Dimensional and Developmental Study. Developmental Neuropsychology, 26, 571-593. http://dx.doi.org/10.1207/s15326942dn2602_3

Catale, C., \& Meulemans, T. (2009). The Real Animal Size Test (RAST): A New Measure of Inhibitory Control for Young Children. European Journal of Psychological Assessment, 25, 83-91. http://dx.doi.org/10.1027/1015-5759.25.2.83

Cohen, J. D., Dunbar, K., \& McClelland, J. L. (1990). On the Control of Automatic Processes: A Parallel Distributed Processing Account of the Stroop Effect. Psychological Review, 97, 332-361. http://dx.doi.org/10.1037/0033-295X.97.3.332

Diamond, A. (2013). Executive Functions. Annual Review of Psychology, 64, 135-168. http://dx.doi.org/10.1146/annurev-psych-113011-143750

Friedman, N. P., \& Miyake, A. (2004). The Relations among Inhibition and Interference Control Functions: A Latent-Variable Analysis. Journal of Experimental Psychology: General, 133, 101-135. http://dx.doi.org/10.1037/0096-3445.133.1.101

Ikeda, Y., Hirata, S., Maeda, W., Okuzumi, H., Kokubun, M., Ambe, H., Fujieda, Y., Suijo, K., Hayashi, J., \& Iteya, M. (2013) Relationship between Stroop/Reverse-Stroop Interference and Postural Sway When Standing in Elderly People. Comprehensive Psychology, 2, 9. http://dx.doi.org/10.2466/22.25.CP.2.9

Ikeda, Y., Hirata, S., Okuzumi, H., \& Kokubun, M. (2010). Features of Stroop and Reverse-Stroop Interference: Analysis by Response Modality and Evaluation. Perceptual and Motor Skills, 110, 654-660.

http://dx.doi.org/10.2466/pms.110.2.654-660 
Ikeda, Y., Okuzumi, H., \& Kokubun, M. (2013a). Age-Related Trends of Stroop-Like Interference in Animal Size Tests in 5to 12-Year-Old Children and Young Adults. Child Neuropsychology, 19, 276-291.

http://dx.doi.org/10.1080/09297049.2012.658364

Ikeda, Y., Okuzumi, H., \& Kokubun, M. (2013b). Stroop/Reverse-Stroop Interference in Typical Development and Its Relation to Symptoms of ADHD. Research in Developmental Disabilities, 34, 2391-2398. http://dx.doi.org/10.1016/j.ridd.2013.04.019

Ikeda, Y., Okuzumi, H., Kokubun, M., \& Haishi, K. (2011). Age-Related Trends of Interference Control in School-Age Children and Young Adults in the Stroop Color-Word Test. Psychological Reports, 108, 577-584. http://dx.doi.org/10.2466/04.10.22.PR0.108.2.577-584

Loher, S., \& Roebers, C. M. (2013). Executive Functions and Their Differential Contribution to Sustained Attention in 5- to 8-Year-Old Children. Journal of Educational and Developmental Psychology, 3, 51-63. http://dx.doi.org/10.5539/jedp.v3n1p51

Ludwig, C., Borella, E., Tettamanti, M., \& de Ribaupierre, A. (2010). Adult Age Differences in the Color Stroop Test: A Comparison between an Item-by-Item and a Blocked Version. Archives of Gerontology and Geriatrics, 51, $135-142$. http://dx.doi.org/10.1016/j.archger.2009.09.040

Macdonald, J. A., Beauchamp, M. H., Crigan, J. A., \& Anderson, P. J. (2014). Age-Related Differences in Inhibitory Control in the Early School Years. Child Neuropsychology, 20, 509-526. http://dx.doi.org/10.1080/09297049.2013.822060

MacLeod, C. M. (1991). Half a Century of Research on the Stroop Effect: An Integrative Review. Psychological Bulletin, 109, 163-203. http://dx.doi.org/10.1037/0033-2909.109.2.163

McDowd, J. M., Oseas-Kreger, D. M., \& Filion, D. L. (1995). Inhibitory Processes in Cognition and Aging. In F. N. Dempster, \& C. J. Brainerd (Eds.), Interference and Inhibition in Cognition (pp. 363-400). San Diego, CA: Academic Press. http://dx.doi.org/10.1016/B978-012208930-5/50012-X

Michel, E., \& Roebers, C. M. (2008). Children in Regular and Special Needs Classes: Cognitive and Non-Cognitive Aspects. Swiss Journal of Psychology, 67, 249-259. http://dx.doi.org/10.1024/1421-0185.67.4.249

Miyake, A., \& Friedman, N. P. (2012). The Nature and Organization of Individual Differences in Executive Functions: Four General Conclusions. Current Directions in Psychological Science, 21, 8-14. http://dx.doi.org/10.1177/0963721411429458

Neuenschwander, R., Cimeli, P., Röthlisberger, M., \& Roebers, C. M. (2013). Personality Factors in Elementary School Children: Contributions to Academic Performance over and above Executive Functions? Learning and Individual Differences, 25, 118-125. http://dx.doi.org/10.1016/j.lindif.2012.12.006

Nichelli, F., Scala, G., Vago, C., Riva, D., \& Bulgheroni, S. (2005). Age-Related Trends in Stroop and Conflicting Motor Response Task Findings. Child Neuropsychology, 11, 431-443. http://dx.doi.org/10.1080/09297040590951569

Nigg, J. T. (2000). On Inhibition/Disinhibition in Developmental Psychopathology: Views from Cognitive and Personality Psychology and a Working Inhibition Taxonomy. Psychological Bulletin, 126, 220-246. http://dx.doi.org/10.1037/0033-2909.126.2.220

Ozonoff, S., \& Jensen, J. (1999). Brief Report: Specific Executive Function Profiles in Three Neurodevelopmental Disorders. Journal of Autism and Developmental Disorders, 29, 171-177. http://dx.doi.org/10.1023/A:1023052913110

Prevor, M. B., \& Diamond, A. (2005). Color-Object Interference in Young Children: A Stroop Effect in Children 31/2 - 61/2 Years Old. Cognitive Development, 20, 256-278. http://dx.doi.org/10.1016/j.cogdev.2005.04.001

Pritchatt, D. (1968). An Investigation into Some of the Underlying Associative Verbal Processes of the Stroop Colour Effect. Quarterly Journal of Experimental Psychology, 20, 351-359. http://dx.doi.org/10.1080/14640746808400174

Roebers, C. M., Röthlisberger, M., Neuenschwander, R., Cimeli, P., Michel, E., \& Jäger, K. (2014). The Relation between Cognitive and Motor Performance and Their Relevance for Children's Transition to School: A Latent Variable Approach. Human Movement Science, 33, 284-297. http://dx.doi.org/10.1016/j.humov.2013.08.011

Röthlisberger, M., Neuenschwander, R., Cimeli, P., \& Roebers, C. M. (2013). Executive Functions in 5- to 8-Year Olds: Developmental Changes and Relationship to Academic Achievement. Journal of Educational and Developmental Psychology, 3, 153-167. http://dx.doi.org/10.5539/jedp.v3n2p153

Song, Y., \& Hakoda, Y. (2011). An Asymmetric Stroop/Reverse-Stroop Interference Phenomenon in ADHD. Journal of Attention Disorders, 15, 499-505. http://dx.doi.org/10.1177/1087054710367607

Wright, I., Waterman, M., Prescott, H., \& Murdoch-Eaton, D. (2003). A New Stroop-Like Measure of Inhibitory Function Development: Typical Developmental Trends. Journal of Child Psychology and Psychiatry, 44, 561-575. http://dx.doi.org/10.1111/1469-7610.00145

Yasumura, A., Kokubo, N., Yamamoto, H., Yasumura, Y., Nakagawa, E., Kaga, M., Hiraki, K., \& Inagaki, M. (2014). Neurobehavioral and Hemodynamic Evaluation of Stroop and Reverse Stroop Interference in Children with Attention-Deficit/ Hyperactivity Disorder. Brain and Development, 36, 97-106. http://dx.doi.org/10.1016/j.braindev.2013.01.005 